\title{
Psychotherapy - Analyzing Conversation of Typical Problematic Situations (TPS)
}

\author{
Michael B. Buchholz ${ }^{1}$ \\ International Psychoanalytic University (IPU)
}

\section{Introduction}

In relation to the psychotherapeutic process, studies have investigated the influence of personality variables (such as socio-economic background, attachment styles, status differences, race, gender) on the one hand, and training orientations (such as Cognitive Behaviour Therapy, psychodynamic, gestalt, systemic), on the other, but results have been largely inconclusive and ambiguous.

After the National Institute of Mental Health-debate between research-groups of Irene Elkin (Elkin, Falconnier, Martinovich, \& Mahoney, 2006) and Bruce Wampold (Kim, Wampold \& Bolt, 2006; Wampold \& Bolt, 2006) 10 years ago, the relevant question to study patient-therapists matching seemed to be conceptualized as a simple and dichotomous 'method or therapist (personality)' dynamic; however, conversation analysis offers another strategy to conceptualise psychotherapeutic dynamics in terms of 'situationism'.

The methodological rules of situationism can be roughly outlined as:

1. Don't look primarily for diagnostic measures as e.g., social background, attachment style, motivation or type of personality. These abstractions produce generic explanations; however, in therapy we look for how these variables (and many others) are individually realized in interaction.

2. Make talk-in-interaction the center of analysis. Such data are gaze, body movements and talk. Talk includes words, the embodied voice and rhythm used to achieve a definition of the situation.

3. Look for how a common ground (Enfield, 2006; Stalnaker, 2002) is established or not. Common ground outlines the horizon we talk to, it is never a "given" but to be established in situations.

4. Talk-in-interaction has the double potential to repair imbalanced common ground and to tear the common ground to pieces.

5. Direct your attention to how common ground activities are managed successfully or not. Without a common ground situationally maintained by interactional and talking activities every special technical procedure in psychotherapy heavily risks to fail.

These guidelines can direct the attention of clinical practitioners and process researchers interested in how such a complex project as 'psychotherapy' is conducted by two people. One could follow Jerome Bruner (1979, preface) who suggested that "interior intellectual work is almost always a continuation of a dialogue." The process of observing of

\footnotetext{
${ }^{1}$ Correspondence concerning this article should be addressed to Prof. Michael Buchholz, International Psychoanalytic University (IPU), Stromstr. 2-3. 10555 Berlin, Germany. Email: michael.buchholz@ipu-berlin.de.
}

Language and Psychoanalysis, 2016, 5 (2), 11-18

http://dx.doi.org/10.7565/landp.v5i2.1557 
conversations is informed by theories that are practiced in situations by focusing on the interactions between two parties (such as practitioners and researchers, or therapists and patients). These observational processes are particularly useful to identify and understand when therapies seem to fail.

Harold Blumer (1969, p. 149) once made a useful distinction by suggesting that "whereas definitive concepts provide prescriptions of what to see, sensitizing concepts merely suggest directions along which to look." Typical Problematic Situations (TPS) is a new sensitizing concept, I do not have a clear cut definition, however a direction where to look. My hope is that one day we might generate a more fully outlined theory of what TPS are and how they can be classified. I use the word "typical" not as a classification marker but as provisional expression of an intuitive sense clinicians have that they have met such a situation often in their professional lifes.

\section{Examples of TPS}

\section{Example 1: Caught in a Controlling-Control Frame}

In a first interview with his psychoanalytic psychotherapist, a young student presents his compulsive symptom with the following words:

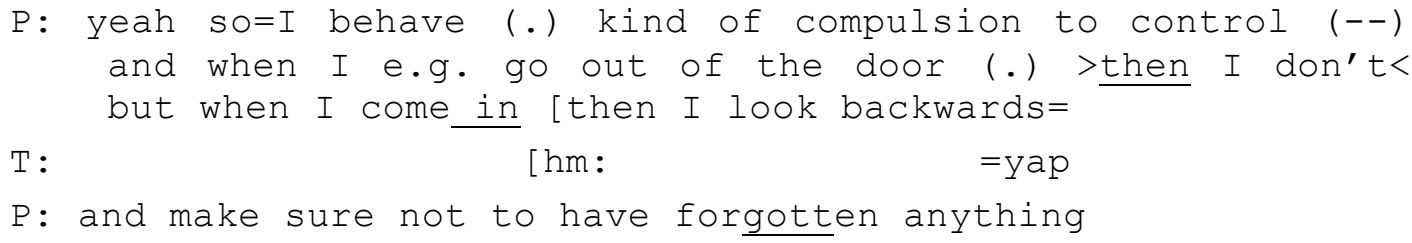

He talks calmly and in an expert manner about his 'compulsion to control' his actions: how he makes sure not to have forgotten something when coming home to his girlfriend from university. He speaks with a "scratchy voice." His expectation of help, the reader learns from studying the whole interview, is to control his controlling behavior. This selfdescription of his symptomatic behavior happens in the first minute of the interview -45 min later we find the following interaction:

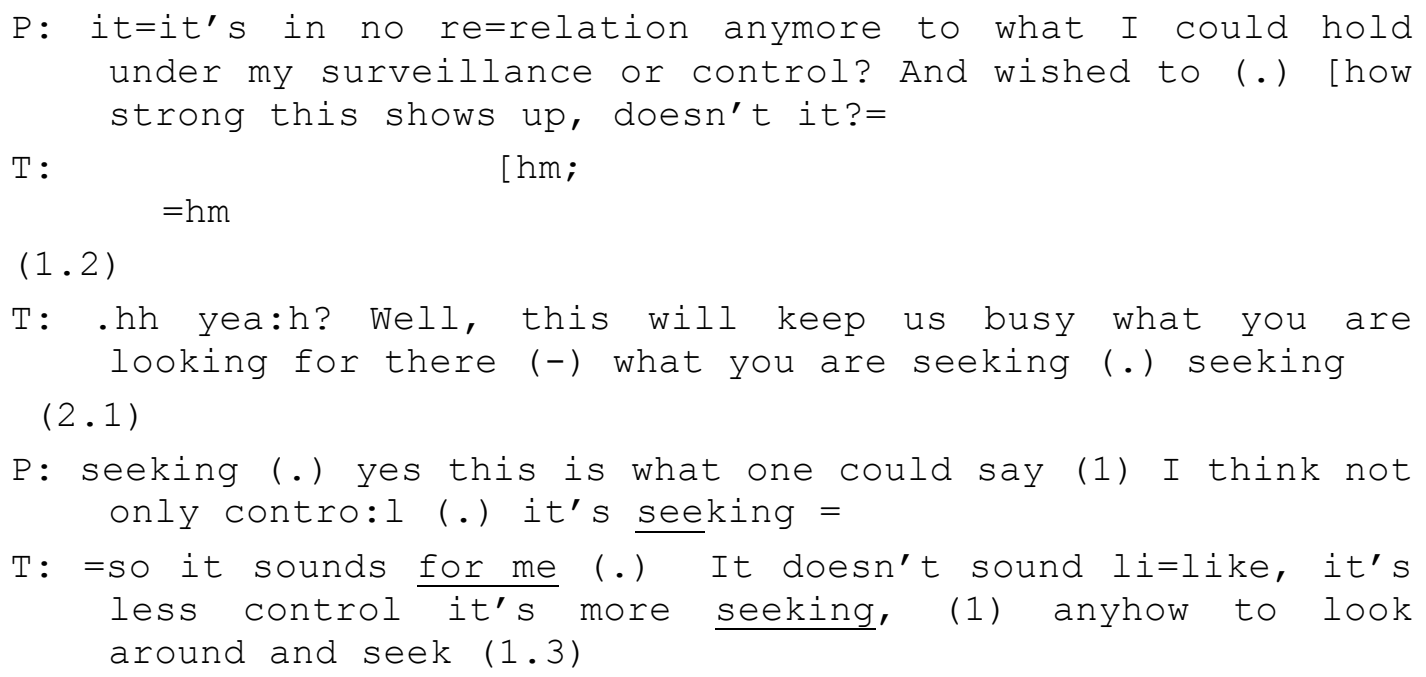


The patient is alarmed how excessive his controlling behavior is. With a somewhat surprised token, the therapist metaphorically formulates (Antaki, 2008) a project for their common work ("this will keep us busy") in the future by replacing "control" by "looking," then "seeking." The patient agreeingly adopts this metaphor and directly acknowledges the therapist's formulation. Now the therapist continues the construction of an alternative agenda (Stivers, 2007) by adding a "look around and seek." The therapist talks with 'high energy'. This is a kind of successful 'persuasive communication' addressing the patient as a seeking person.

\section{Example 2: Needing Help and Nobody Can Help}

There are other TPS's where therapeutic engagement is urgently demanded. A severely depressed woman in her late twenties begins her $30^{\text {th }}$ therapy session as follows:

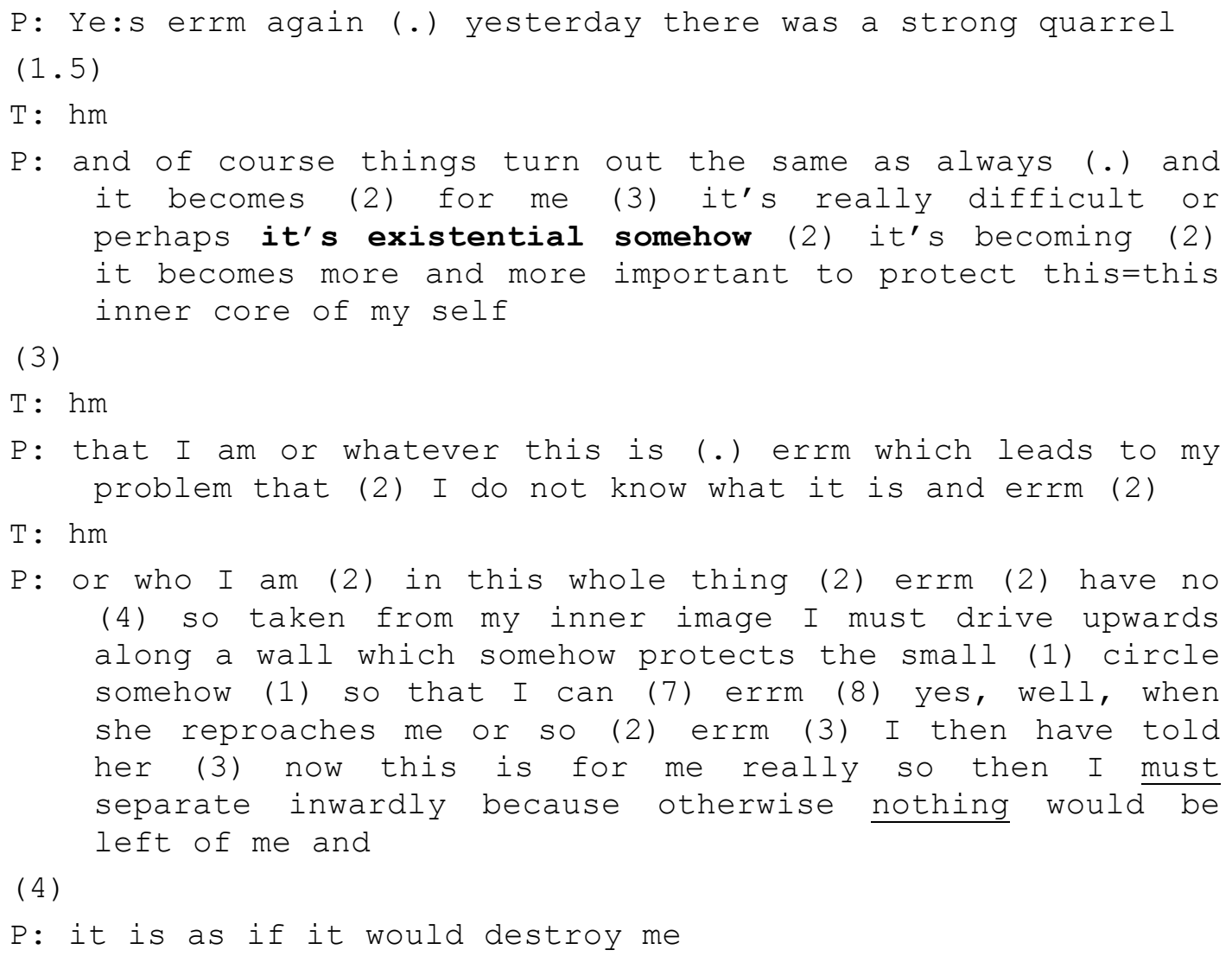

This TPS is composed of several interactional details. First, the patient's talk is full of self-interruptions. Many sentences are started, but left unfinished. Many new topics without completion. Listeners are set under tension: What might be relevant next? Every topic is relevant, but the fast series of relevance systematically downgrades every single topic (Körfer \& Köhle, 2007). Second, by telling to present things as "always in the same way" (line 4) she utters the expectation that her therapist will be bored while listening to "the same as always." The wave of up- and downgrading relevance has interactive effects: On the one hand, she shows consideration of her therapist's mood which leads her to inhibit full story telling; on the other hand, she increases her demands for help, third, by outlining an existential dimension of her threatened core self when (line 9-12) she does "not know" adding "or who I am in this whole thing." Fourth, she intensifies her 
symptomatic complaints; she suffers from a powerful and paradoxical "inner image" (line 12) to drive along a wall that protects and encloses her; someone reproaches her, she has to protect herself against being destroyed (line 18).

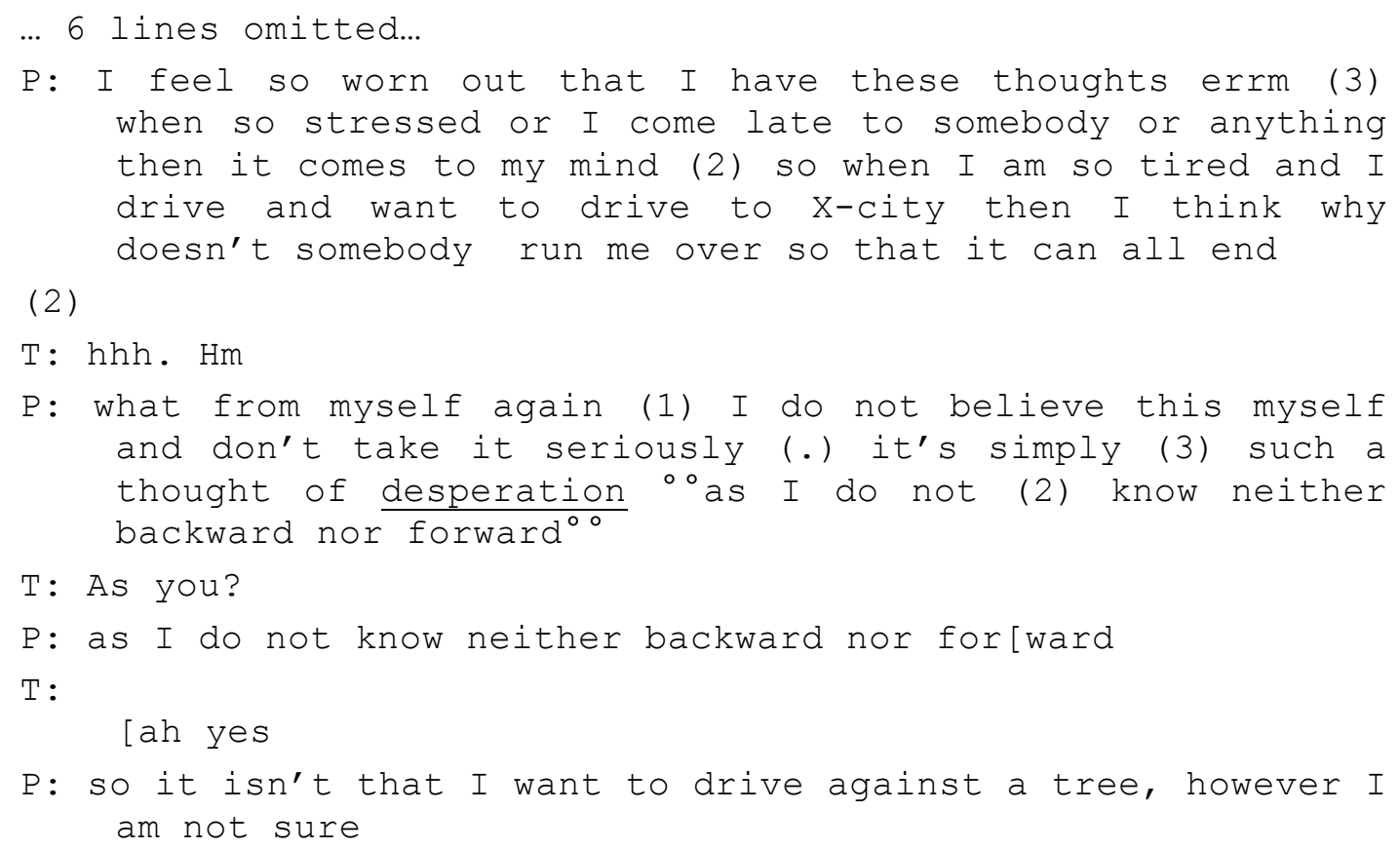

She is so worn out that she feels an impulse to bring things to an end ("somebody run me over" and "to drive against a tree"). Fifth, while increasing her symptomatic complaints the therapist utters hardly more than go-ahead-tokens. The patient emphasizes her sense of desperation that she knows neither backward nor forward (line 31). As her therapist asks for a repetition of the phrase not-understood the patient loudly repeats and the therapist utters an "information-received token" (line 34). In summary, it is as if the patient would say, "I need your help urgently; however, nobody can help me, not even you!"

It could be a valuable task for CA in cooperation with clinicians to propose what kind of conversational strategy might be helpful in such a TPS. How to overcome false considerateness and blackmail, in order to transform the TPS into a workable position?

\section{Another example of the same kind}

Another example from our CEMPP-material has some common features, one of which is the sequentiality of patient's complaints and therapist's "information received tokens." I do not show this but another course of treatment.

This patient, a male professional with family and children, came to therapy after having committed a suicide attempt. He successfully deceived major parts of his family and professional environment about his suicide attempt. He simply lied. However, his state has not improved. He sees no solution and he wishes to withdraw from life completely. He complains about his inability to lead a normal life, he accuses himself to be a burden to his wife, his children and colleagues. Pills a doctor prescribed worsened his situation. In his 17 th session after a long series of complaints something different happens: 


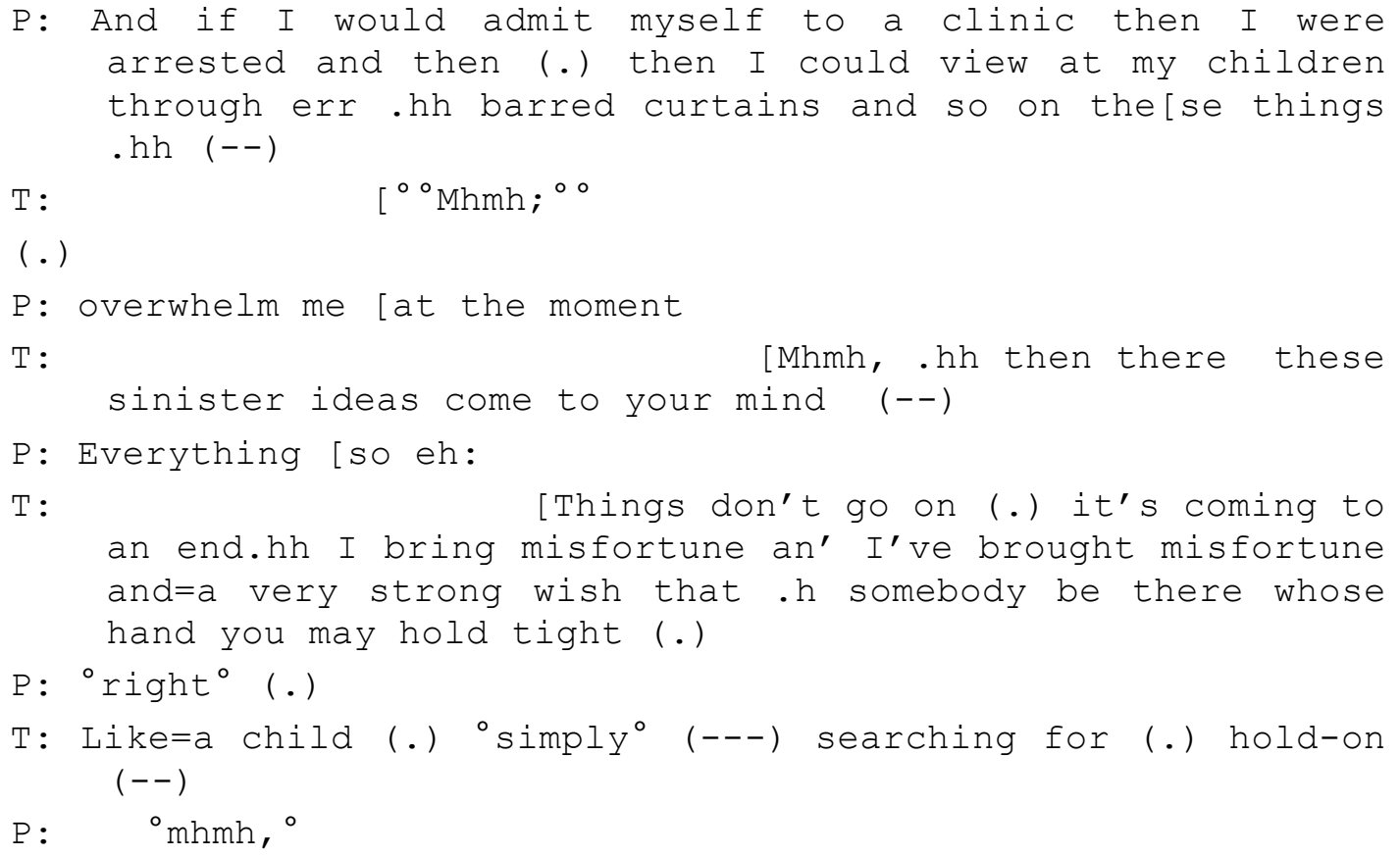

First, the therapist does not refer to the single content of the many complaints, but understands them as examples for an overall mental state ("these sinister ideas") the patient attempts to convey to the therapist. The therapist exemplifies empathy. Second, the therapist does it by using a theoretically inspired metaphor of childhood experience: searching for a hand to hold on. Thirdly, the therapist minimizes the risk of blaming by a shift of positioning. He uses the pronoun "I" where obviously he paraphrases the patient's accusations to have brought misfortune to many people. Thus, the therapist lets the patient know that he, the therapist, knows such states-of-mind as well. A re-normalizing might be effected. Taken together all these measures seem to calm the patient's state for 11.8 seconds, which is the first pause in the session. It could be considered a reflective pause (Frankel, Levitt, Murray, Greenberg \& Angus, 2006).

However, so simply a seriously depressed patient's complaints cannot be cured. The patient comes up with a lot of similar complaints and two minutes later the following sequence is enacted:

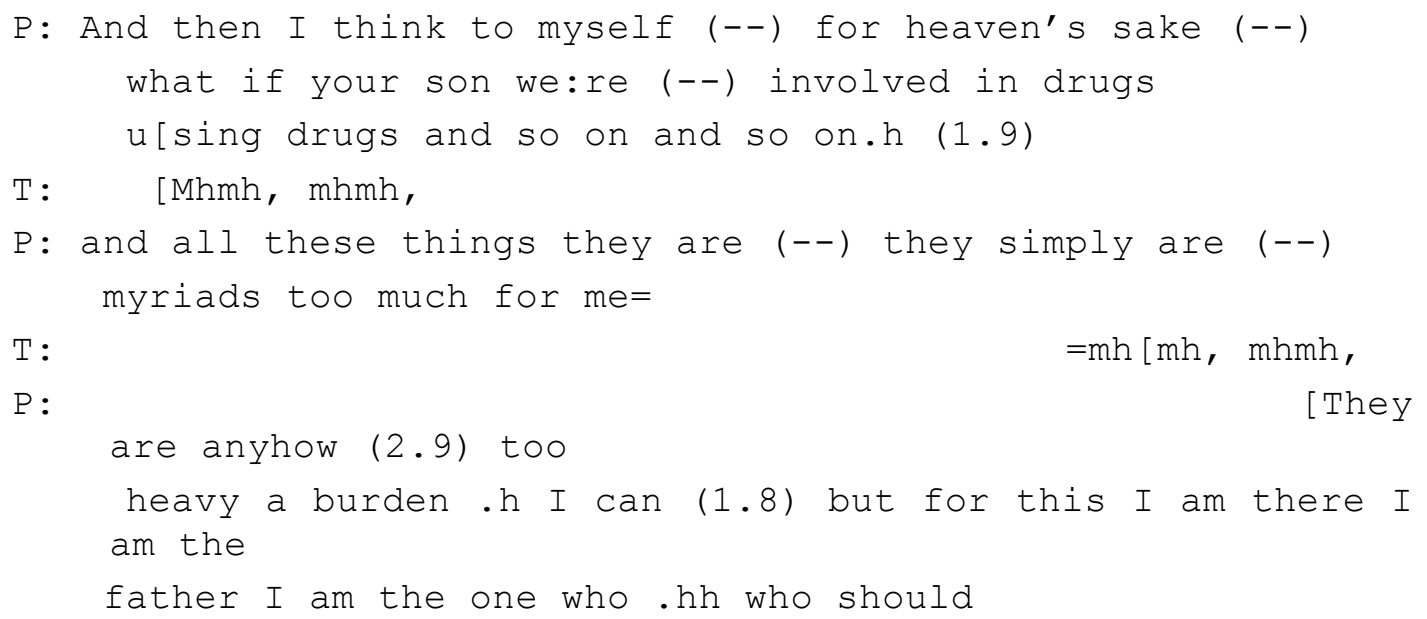




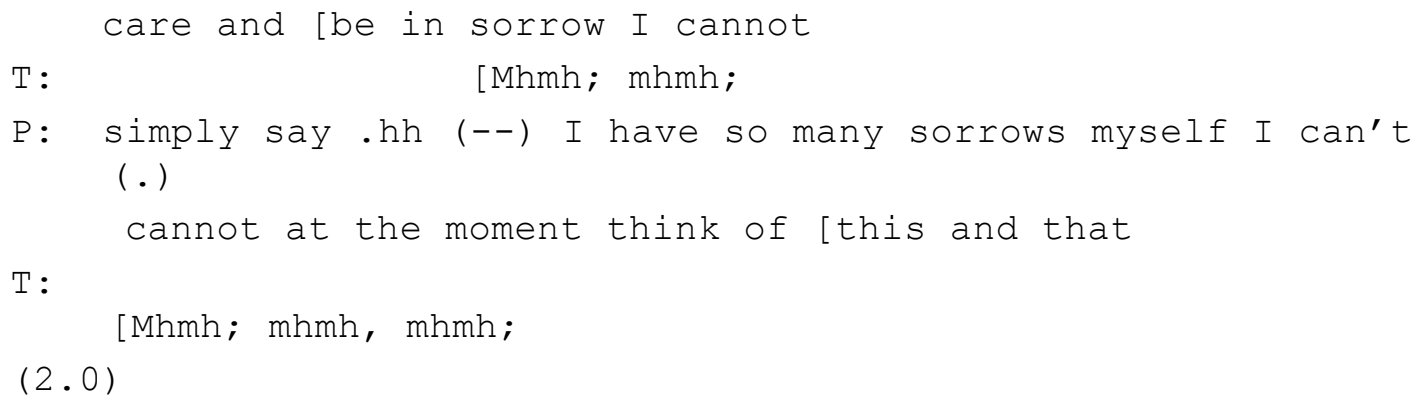

Changing to the topic of caring for his own children the patient seems to indicate why he is unable: because he feels as a child as the therapist uttered a few seconds before. Feeling a child himself his children become an unbearable burden. Accusingly he appeals to himself that he is the father:

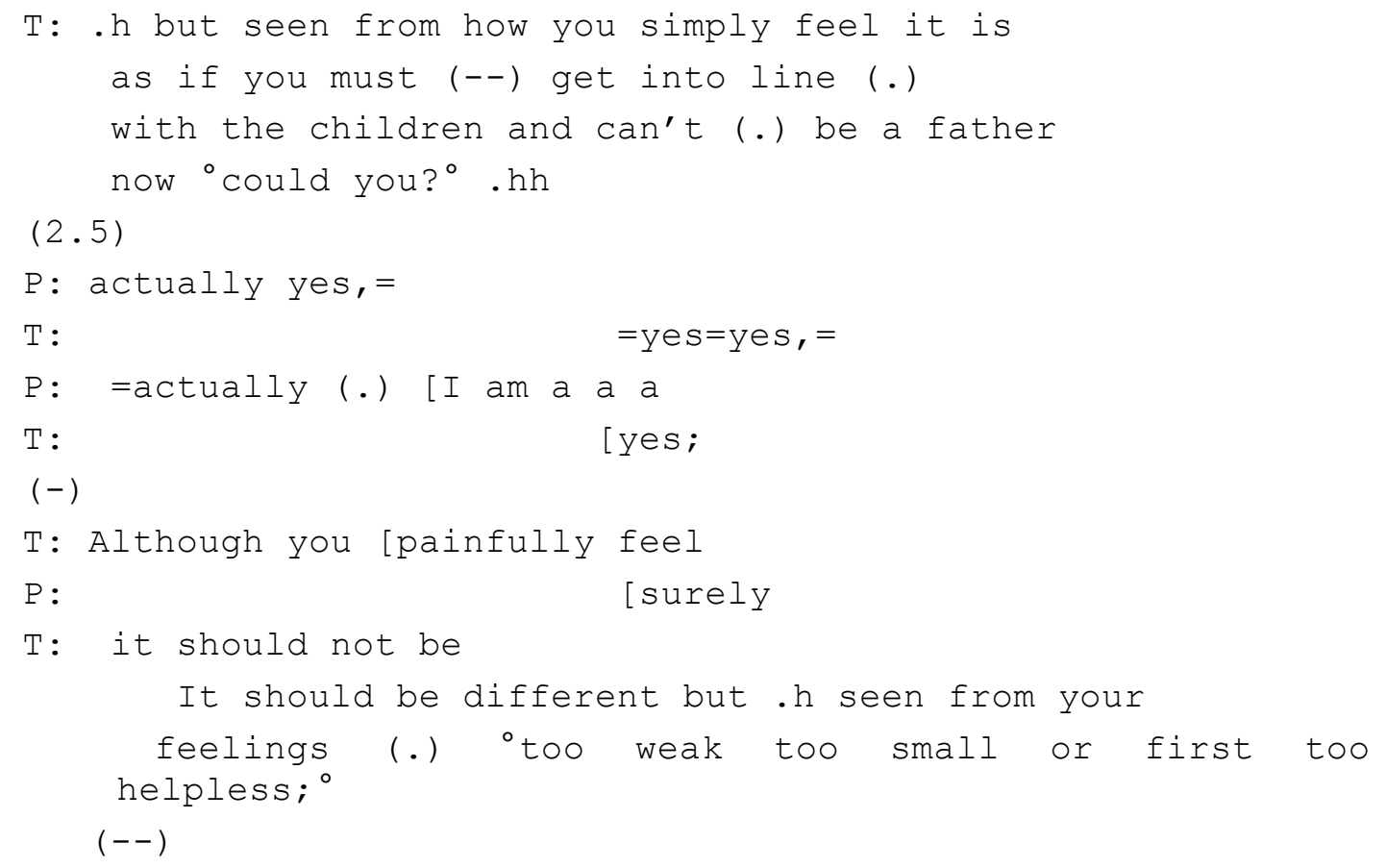

We find the therapist using the metaphor of a child in a way the patient can easily accept (428). This is later dramatically confirmed by the patient telling that he sleeps in his children's room to feel their closeness. The therapist affiliates with the patient's helplessness by doing what he is talking about - taking the "child's" hand. This is more than positioning, it is therapeutic agency (Berán \& Unoka, 2015). This segment, finally, results in what Lerner (Lerner, 2013) has called 'other completion'.

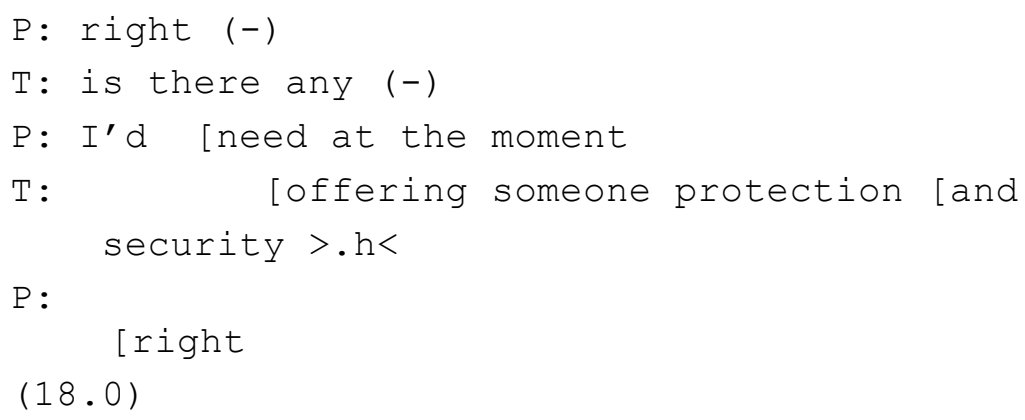


Both participants begin to move into a micro-universe of distributed knowledge mutually completing their sentences. This type of collaboratively co-constructed utterances is described by Hutchins and Nomura (2011, p. 29) in the following way:

In the most frequently studied type of collaboratively constructed utterance, one speaker begins an utterance in a way that projects possible completions. Another speaker then contributes utterance elements that are incorporated into a jointly produced utterance. The acceptance by participants of a collaboratively constructed utterance is strong evidence for the establishment of common ground understanding.

The solution for this TPS establishes a common ground by shifting I-positions with an effect of down-grading the risk of blaming, reformulating some of the patient's utterances and outlining his state-of-mind in a way that confirms that both share distributed knowledge with an effect of renormalising the patient's state-of-mind, which has a soothing effect.

\section{Concluding Remark}

After this analysis we can describe further aspects of situationism: Two persons, meeting in mutually unknown biographical and partially shared cultural contexts which they produce and reproduce, and an interaction "face-to-face" (Jaegher, Peräkylä, \& Stevanovic, 2016). Both participants bring in their capacities of sense-making and their bodies, above all their voice, which is immediately perceived and mutually reacted to. Skills of social understanding are required while each participant knows that a high degree of unpredictability is co-present with a more or less high level of emotional arousal. These components are brought together in order to achieve some meaningful interaction while working on the common project of "psychotherapy" which is broken down into many smaller part-projects . However, Goffman's formulation at the end of his 1967 "Introduction" to "Interaction Rituals" can serve as an orientation: "a psychology is necessarily involved, but one stripped and cramped to suit the sociological study of conversation, track meets, banquets, jury trials, and street lotering" not, then, men and their moments. Rather, moments and their men" (p. 3). It is these moments, which clinicians know from one patient to the other and from one consulting room to the inhabitants of other consulting rooms. Studied as sequence of situations or moments, it is the foundation of typicality. This and more is a challenge for the future. 


\section{References}

Berán, E., \& Unoka, Z. (2015). Reconstructing agency by shifting perspective in trauma narrative. Language and Psychoanalysis, 4, 50-74.

Blumer, H. (1969). Symbolic interactionism. Berkeley, CA: University of California Press.

Bruner, J. S. (1979). On Knowing: Essays for the Left Hand. Cambridge, MA: Harvard University Press.

Elkin, I., Falconnier, L., Martinovich, Z., \& Mahoney, C. (2006). Therapist effects in the National Institute of Mental Health Treatment of Depression Collaborative Research Programm. Psychotherapy Research, 16, 144-160.

Frankel, Z., Levitt, H. M., Murray, D. M., Greenberg, L. S., \& Angus, L. E. (2006). Assessing silent processes in psychotherapy: an empirical derived categorization system and sampling strategy. Psychotherapy Research, 16, 627-638.

Goffman, E. (1967). Interaction ritual; Essays on face-to-Face behavior Garden City, NY: Doubleday.

Hutchins, E., \& Nomura, S. (2011). Collaborative Construction of Multimodal Utterances. In J. Streeck, C. Goodwin, \& C. D. LeBaron (Eds.), Learning in doing : social, cognitive and computational perspectives. Embodied interaction. Language and body in the material world (pp. 29-43). New York, NY: Cambridge University Press.

Jaegher, H. de, Peräkylä, A., \& Stevanovic, M. (2016). The co-creation of meaningful action: Bridging enaction and interactional sociology. Philosophical Transactions of The RoyalSociety@Biological Sciences.

Kim, D.-M.-M., Wampold, B. E., \& Bolt, D. M. (2006). Therapist effect in psychotherapy: A random-effects modeling of the National Institute of Mental Health Treatment of Depression Collaborative Research Programm data. Psychotherapy Research, 16, 144-160.

Koerfer, A., \& Koehle, K. (2007). Kooperatives Erzählen. Zur Konstruktion von Patientengeschichten in der ärztlichen Sprechstunde [Cooperative narration. The construction of patients' narrative in medical communication]. In A. Redder (Ed.), Diskurse und Texte - Festschrift für Konrad Ehlich zum 65. Geburtstag (pp. 629639). Tübingen, Germany: Stauffenburg Verlag Brigitte Narr GmbH.

Lerner, G. H. (2013). On the place of hesitating in delicate formulations: a turnconstructional infrastructure for collaborative indiscretion. In M. Hayashi, G. Raymond, \& J. Sidnell (Eds.), Studies in Interactional Sociolinguistics: Vol. 30. Conversational repair and human understanding. (pp. 95-134). Cambridge, UK: Cambridge University Press.

Stivers, T. (2007). Treatment decisions: negotiations between doctors and patients in acute care encounters. In J. Heritage \& D. W. Maynard (Eds.), Communication in medical care. Interaction between Primary Care Physicians and Patients (pp. 279313). Cambridge, UK: Cambridge University Press.

Wampold, B. E., \& Bolt, D. M. (2006). Therapist effects: Clever ways to make them (and everything else) disappear. Psychotherapy Research, 16, 184-187. 